\title{
Analysis of Energy Performance on Envelope Ratio Exposed to the Outdoor
}

\author{
Hong Soo Lim and Gon Kim (D) \\ Department of Architectural Engineering, Kyung Hee University, Yongin 446-701, Republic of Korea \\ Correspondence should be addressed to Gon Kim; gonkim@khu.ac.kr
}

Received 26 October 2017; Revised 3 March 2018; Accepted 27 March 2018; Published 2 May 2018

Academic Editor: Constantin Chalioris

Copyright (c) 2018 Hong Soo Lim and Gon Kim. This is an open access article distributed under the Creative Commons Attribution License, which permits unrestricted use, distribution, and reproduction in any medium, provided the original work is properly cited.

\begin{abstract}
The shape of a building largely contributes to its energy consumption. The current study utilized metrics of surface-to-volume ratio, surface-to-floor ratio, area-to-perimeter ratio, and volume ratio to evaluate building energy performance. Also, the paper focused on the relation between the air-conditioned room and non-air-conditioned room. This approach affects both the design stages of the floor plan and the main designing factors that decide which spaces would become air-conditioned spaces such as those mostly occupied by residents or non-air-conditioned space such as staircases and elevators. The heating load and cooling load were calculated using the new equation based on the location of non-air-conditioned spaces and envelope ratio facing the outdoor. Both the width-depth ratio and envelope ratio were analyzed using the IES_V.E (Integrated Environmental Solutions Virtue Environment) program. It turns out that, as the non-air-conditioned spaces increase, both heating load and cooling load were reduced.
\end{abstract}

\section{Introduction}

The example building utilized in this study is that of an apartment building in South Korea. It was initially developed to contain the latest information technology as well as high-rise building technology. The term "apartment building" in Korea is used to describe apartment houses that are sold in lots rather than being leased. At times, high-rise apartment buildings are also referred to as apartment towers. Apartment buildings have been built since 1960 and are therefore widely represented. As of 2010, this kind of building type accounted for $53 \%$ of residential buildings. However, these same types of buildings are currently facing a number of issues related to standardization, agglomeration of high-rise buildings, and unsold subdivision houses as a result of the excess number of such buildings that are in existence today.

Also, the recent government law on balcony expansion has brought up a number of issues related to energy consumption in buildings [1]. In addition, other issues ranging from neighbors' complaints of noise, decrease in property value, and so forth have given rise to pressing concerns. As a result, architectural companies have come up with a variety of apartment plans with hopes to successfully meet the demands of consumers. Among many methods utilized for the purposes of identifying apartment types, the "BAYconception" is the most commonly used one (Figure 1). Generally, in this method, the main factors constituting the architectural environment of a space such as $U$-value of windows and walls, building orientation, ventilation, and daylight performance are considered.

$U$-value is determined through the thorough analysis of the conductivity properties of the construction materials that make up parts of a space. In the past, researchers have presented critical knowledge regarding window-to-floor ratio and window-to-wall ratio [2]. However, the knowledge that exists in the current publications only focuses on the relation between floor plans and energy consumption of buildings on individual case basis rather than in a general manner. Therefore, the purpose of the current study is to analyze energy performance regarding the relationship between air-conditioned space and non-air-conditioned space 


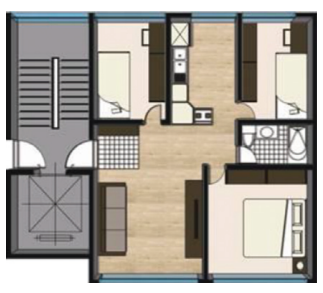

(a)

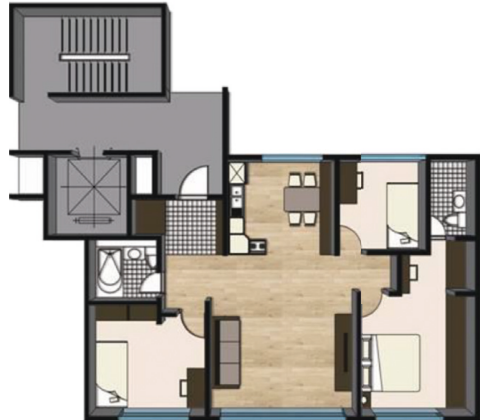

(b)

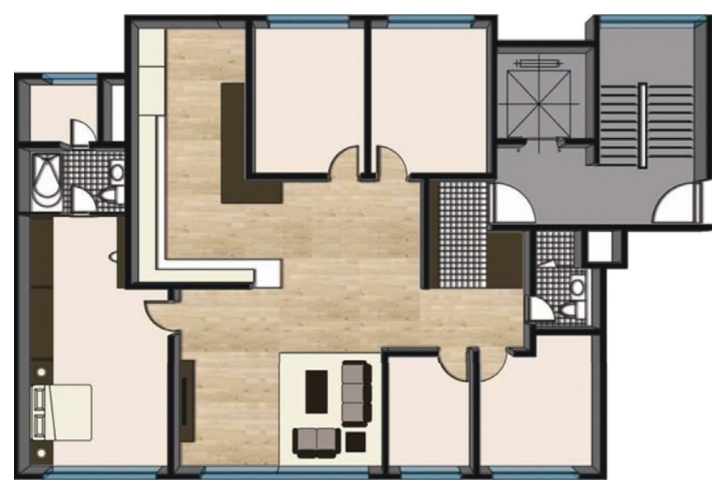

(c)

Figure 1: Concept of BAY in South Korea. (a) 2 BAY, (b) 3 BAY, and (c) 4 BAY.

of an entire space and provide a general equation that connects floor plans to the energy performance of a given building.

\section{Literature Review}

Different building shape geometries were analyzed by Menkhoff et al. [3]. Geometric compactness is obtained by dividing the area of external walls by the volume of the building. Different building geometries were introduced using four similar cubes. As a result, four geometrical compactness coefficients ranging from $4 / a$ to $14.1 / a$ were obtained. Also, with reference to a study by Petzold [4], a building with a shape of a rectangular prism was optimized. In doing so, heat gains through transparent and opaque partitions were taken into consideration. This same criterion of minimum heat requirement was utilized in the current study to determine the relation between the length of the walls and the maximum number of floors.

Also, AlAnzi et al. [5] studied on the impact that building shapes had on the energy efficiency of office buildings in Kuwait. The research focused on a variety of factors such as building shapes, window areas, and so forth. In the end, a model able to predict the effect that building geometry has on energy performance of buildings with different glazing and window-to-wall ratio was developed through a comprehensive parametric analysis, Firstly, the parametric analysis were conducted by a simulation tool followed by a presentation selected parametric analysis results. Furthermore, a simplified calculation method that links building energy usage to the geometry of the building, window sizes, and glazing type is developed.

In a similar study, Pessenlehner and Mahdavi [6] developed variables based on 18 cubical elements. They assembled and connected the cubes to make different building shapes and compared heating and cooling loads belonging to different building shapes. This approach was inspired by the common idea that some building energy standards utilize simple numeric indicators to describe the geometric compactness of a building. The indicators follow the relation between the surface area of a space and the volume of its built form. These indicators are then utilized together with the information on the $U$-values of the building material elements to evaluate the extent to which a building design meets a given thermal insulation criterion.

The shape coefficient can be defined as the ratio of the external envelope to the volume of the inner building space. In the study by Depecker et al., fourteen buildings of different shapes were chosen. The frequency of their existence in today's construction market was also considered. The calculation approach utilized in the evaluation of heating consumption is also briefly described. Depecker et al. indicates that the buildings' shape as being directly proportional to its external wall surfaces [7].

$\mathrm{Su}[8]$ also analyzed diverse factors such as the ratio of building surface and building volume, window size and wall area, orientation of window and building materials. He also indicates a link between increased mean daily energy consumption and building shape and design. This further increases research interests related the relationship building design and building energy consumption. The study also strongly emphasizes that building design elements related to architectural features be given paramount consideration in order to successfully construct passive energy buildings.

In hot-humid climate, buildings experience a significant amount of heat gains. Ling et al. [9] examined the relationship between building shape and direct sunlight received by tall buildings located in hot and humid climates. He studied square and rectangular-shaped buildings with different width-to-length ratios and oriented to different directions. This was done using a computer simulation tool. The results revealed that circular-shaped building with a width-to-length ratio of $1: 1$ is most likely to experience reduced heat gains as compared to a rectangular-shaped building of the same width-to-length ratio.

Capeluto [10] focused on the absorption of direct sunlight by the building envelope. In his study, he explained the general factors related to the shape of the building during the preliminary stages of building design. These factors include the height of the building relative to the size of the street where it dwells, facade orientation, and the size of building elements. Finally, he suggested the use of building shape as a solar collection envelope to counter the effect of heat gains due to insolation. 


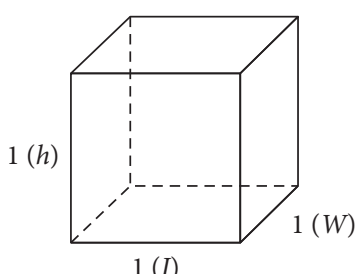

$(1: 1: 1)$

Surface area

$A=2(w h+l w+l h)$

$=6$

(a)

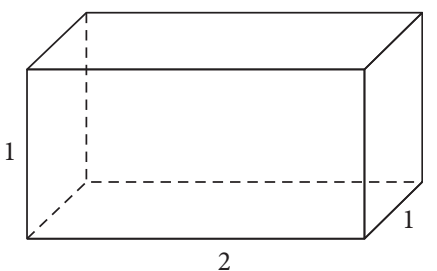

$(1: 2: 1)$

Surface area

$A=2(w h+l w+l h)$

$=10$

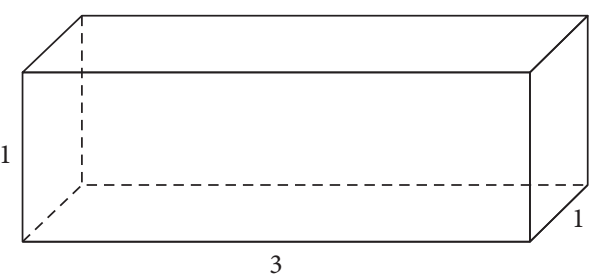

$(1: 3: 1)$

Surface area

$A=2(w h+l w+l h)$

$=14$

(b)

(c)

FIGURE 2: Surface-to-volume ratio.

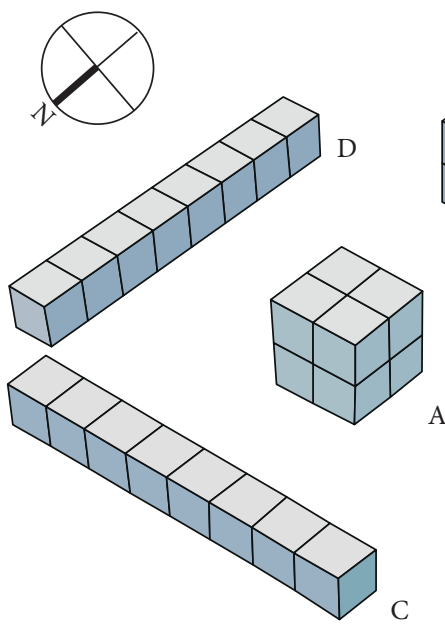

(a)

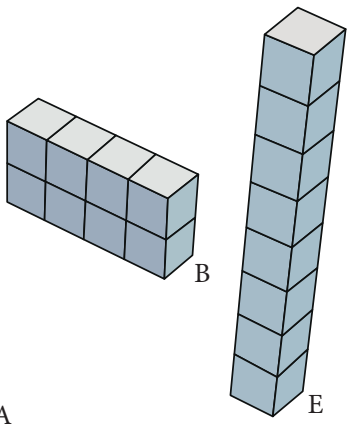

A: $S / V=2.5$

B: $S / V=3.0$

C: $S / V=3.25$

D: $S / V=3.25$

E: $S / V=4.13$

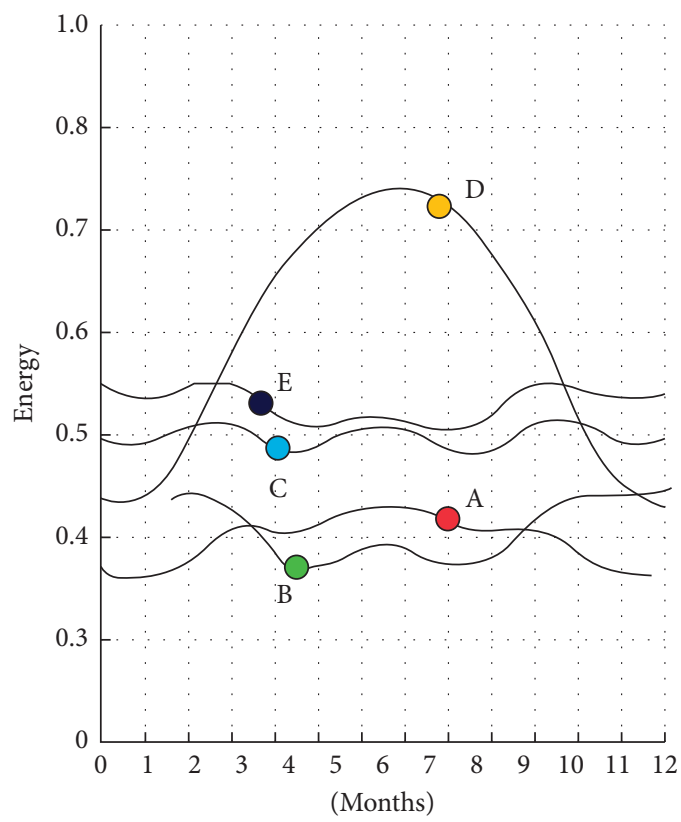

(b)

FIGURE 3: Surface-to-floor area ratio.

\section{Methodology}

3.1. Coefficient Ratio. The surface/volume ratio is able to explain the relation between the envelope areas and volume of the space and can be used to evaluate the heat loss in buildings. Generally, when the surface of the envelopes is smaller than the volume they occupy, heat losses through convection or radiation are reduced (Figure 2) [11].

Although the method can be an important index in predicting the shape of the building, it cannot be used to predict building energy performances in detail without considering other factors such as windows and building orientation. This is because the overall energy performance is influenced by the $U$-value of window or wall compositions. Also, the ventilation acquired as a result of building orientation and window opening mechanisms has an effect on the energy use of the building. Thus, for any given space without windows, the surface/volume ratio could be used as a criterion for evaluating energy performance. Figure 3 shows the concept of the surface-to-floor area ratio. Several buildings have different amounts of direct radiation penetrating their facades depending on the orientation and the disposition of cubes. The larger or higher the building, the higher the energy usage. This is due to the surface-tofloor area ratio and the surface-to-volume ratio being higher in higher and larger buildings. In case of low buildings, the surface-to-floor area ratio is sharply reduced. On the other hand, the reduction rate of the surface-to-floor area ratio is reduced or marginalized in case of over 20 floors of cubes.

The area-to-perimeter ratio is the ratio between the area of space and its perimeter length. If two given spaces have an identical area-to-perimeter ratio, their shapes and volumes are not identical. In order to solve such problems, the compactness ratio based on the circular space was calculated 


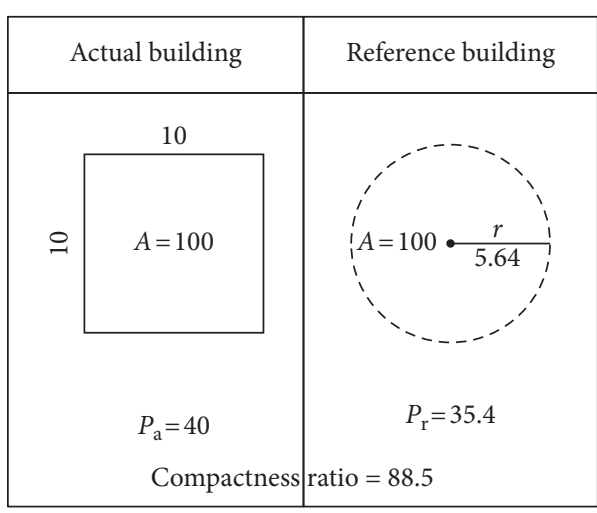

(a)

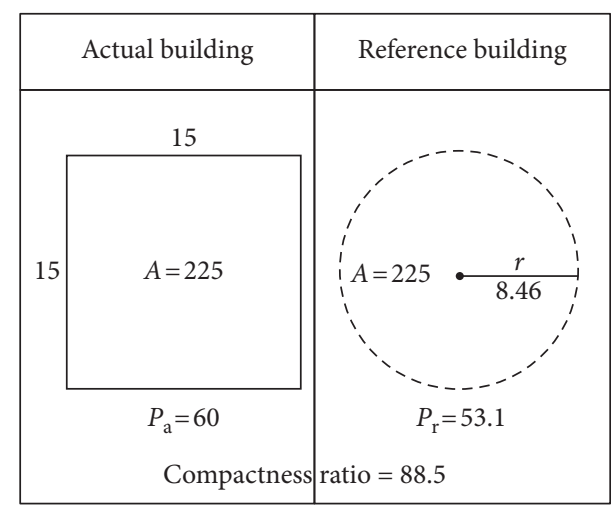

(b)

FIgURE 4: Area-to-perimeter ratio [12].

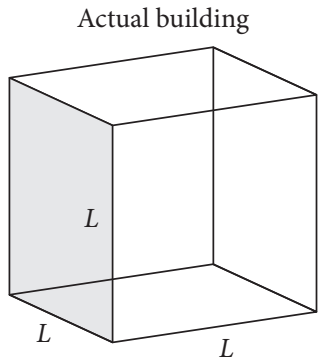

(a)

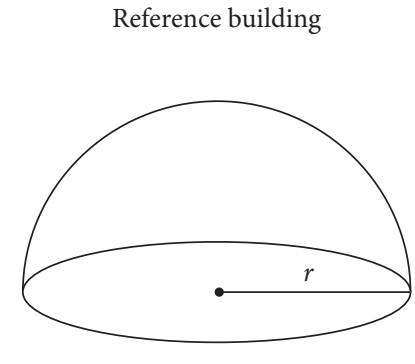

(b)

FIgURE 5: Volume ratio [12].

using (1) (Figure 4). The volume ratio is a method that utilizes hemispheres with identical volumes. Equation (2) is for the volume ratio.

Area-to-perimeter ratio refers to the ratio between the sizes of the space bounded by a given object to the total distance around the object. Two given spaces shown in Figure 4 are of equal area but different perimeter. For this case, the compactness ratio was calculated using the following equation:

$$
\mathrm{POP}=\frac{P_{\mathrm{a}}}{P_{\mathrm{r}}} \times 100 \% \text {, }
$$

where $\mathrm{POP}=$ compactness ratio, $P_{\mathrm{a}}=$ perimeter of the actual building, and $P_{\mathrm{r}}=$ perimeter of the reference building.

The volume ratio was also calculated for Figure 5. The Figure contains a hemisphere and a cube of equal volumes but different surface areas. The hemisphere and the cube represent the reference building and actual building, respectively. The volume ratio was calculated using the following equation:

$$
\text { volume ratio }=\frac{S_{\mathrm{a}}}{S_{\mathrm{r}}} \times 100 \%,
$$

where $S_{\mathrm{a}}=$ surface area of the actual building and $S_{\mathrm{r}}=$ surface area of the reference building.

3.2. Variables. In determining effect of building shape and orientation on building heating demand, the first step should be to calculate surface temperatures belonging to both opaque and transparent surface skins of the building. Also, in estimating the cooling load that arises from wall radiations or transmission through windows, determining the average amount of direct sunlight reaching the earth on any given day of the year is of paramount importance. Furthermore, understanding the characteristics of direct sunlight and its reflections on shapes with different geometry and orientations are of crucial importance as well.

In this paper, the window area was fixed and compared with the energy performance according to the ratio between air-conditioned space and non-air-conditioned space. Namely, the ratio is related to envelope's area exposed to the weather. The non-air-conditioned space was extended from the building left wall facing west to east.

$$
x=100 \times \frac{\rho}{a+2 b+c+d},
$$

where $a: b=$ width and depth ratio air-conditioned ratio, $a+b+c+d=$ circumference without window, $\rho=$ length of area adjacent to the perimeter space, and $x=$ non-airconditioned and air-conditioned ratio.

To create variables for this research, the relationship between air-conditioned and non-air-conditioned space needs to be clearly defined. The variables are explained in Figure 6 and (1). Symbol " $a$ " means space's width whereas " $b$ " indicates the space's depth. The relation between " $a$ " and " $b$ " is the ratio of lateral to longitudinal length. Symbol " $\rho$ " 


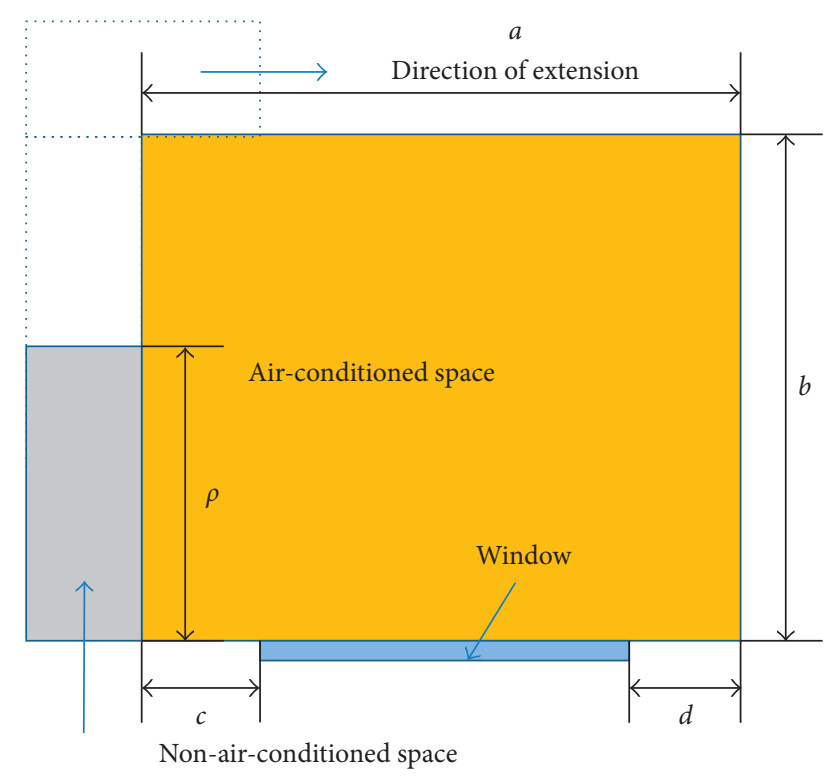

FIGURE 6: Methodology of creating variables.

indicates the dimension of air-conditioned space that is in connection with non-air-conditioned space. Symbol " $x$ " calculated by (3) is estimated by the value from non-airconditioned and air-conditioned ratio. When the value " $x$ " increased, non-air-conditioned space ratio decreased. As such, " $x$ " is defined as the percentage of the length of area adjacent to the perimeter space divided by the surface area of the air-conditioned space excluding the glazing area. The size of window is $6 \mathrm{~m}$ (width) $\times 2 \mathrm{~m}$ (height).

3.3. Modeling for Simulation. IES_V.E (Virtual Environment) program is made by Integrated Environmental Solutions Ltd. founded by Dr. Don McLean in Strathclyde University. IES_V.E is a tool used in the analysis of building energy performance. It contains applications such as ModelIT, ApacheSim, RadianceIES, SunCast, and MacroFlo. These applications are linked to user input data for integral thermal simulation. ModelIT is a 3D modeler for dynamic thermal simulation. ApacheSim is based on the ASHRAE Heat Balance Method. The material property and indoor conditions used in the current study are those offered by ENISO13370 and ASHRAE 90.1, the results are presented by EN-ISO13370 and ASHRAE 90.1. RadianceIES program is an interface for analysis of daylighting performance. The program shows the illuminance and luminance in indoor spaces. SunCast is able to analyze the shading effect of surrounding buildings and shading devices. Lastly, MacroFlo is used to calculate the ventilation and infiltration levels using a network model [13].

For the purposes of analyzing energy performance, two different spaces with dimensions 8 meters-by- 8 meters and 16 meters-by- 4 meters were modeled using the IES-V_E (Virtual Environment) program. The thermal properties used for the modeling of the spaces are as indicated in Table 1. Three layers of construction materials were used to offset the effect of sol-air temperature resulting from direct solar radiation. In addition, an extra floor was modeled on top of the first floor to eliminate the impact of geothermal heat. Following the thermal comfort criteria, the highest temperature was set to $26^{\circ}$ during the cooling period and $20^{\circ}$ in the heating period. Ventilation and infiltration rates were set to $0.7 \mathrm{ACH}$ and $0.25 \mathrm{ACH}$, respectively [14]. Table 1 shows material properties and conditions utilized for the simulation process.

All windows in the reference building were closed because the research mainly considered the effect brought upon by natural ventilation. Although the direct sunlight was also not considered for only extreme results, the reference building without windows does not exist in reality. Thus, the windows were installed facing south, and the material properties are represented in Table 1.

Generally, the internal heat gains resulting from occupant activities or mechanical operation together with other heat sources (indoor heat sources and direct solar radiation) can lead to very high temperatures in summer. Minimizing these temperatures becomes the first priority in designing a comfortable indoor environment [15]. Thus, this paper did not consider the effect of internal heat gains on exposed envelopes.

\section{Results}

4.1. Weather Data. The used weather data were collected by the Korea Meteorological Administration (KMA) and distributed by the Korean Solar Energy (KSA) society. The data were used to conduct energy performance simulations in residential buildings.

Seoul city in South Korea is classified as Dwa (continental dry winter hot summer) of Köppen-Geiger climate classification system [16]. As of 30 years (1981-2010), the average annual temperature in Seoul was $12.5^{\circ} \mathrm{C}$, the average temperature in August was $25.14^{\circ} \mathrm{C}$, and the average temperature in January was $-2.52^{\circ} \mathrm{C}$ (Figure 7 ).

The average temperature for the coldest month is especially lower than other cities located on the same latitude. The periods in summer and winter are longer than those in spring and fall, and usually cooling period starts from June to September. Heating period lasts from October to February. In general, heating load in typical residential building is approximately eight times higher than cooling load.

The spring begins in the middle of March when the average temperature rises by more than $0^{\circ} \mathrm{C}$ to warm up and last until about May, when it rises by more than $20^{\circ} \mathrm{C}$ from June.

By geographical location, Seoul is affected by the heat and humidity of the southeast from the Pacific Ocean during the summer and by the dry and cold winds blowing from the continent in the winter.

Seasonal precipitation is concentrated during the summer in South Korea, but the annual average precipitation is about $1,450.5 \mathrm{~mm}$ but not constant due to the irregular rainfall.

Figure 8 shows the monthly global solar radiation in daytime during 30 years (1981 2010). Given that Seoul's latitude is $37.5^{\circ}$, the meridian transit altitude is $76^{\circ}$ in summer solstice. Generally, solar radiation depends on solar 
TABLE 1: Material properties and conditions of the computer model.

\begin{tabular}{|c|c|c|}
\hline Construction & Description & $U$-value $\left(\mathrm{W} / \mathrm{m}^{2} \mathrm{~K}\right)$ \\
\hline Ground/exposed floor & $\begin{array}{c}\text { Concrete }(180 \mathrm{~mm})+\text { insulating material }(65 \mathrm{~mm}) \\
+ \text { cultivated sandy soil }(40 \mathrm{~mm})+\text { polystyrene }(65 \mathrm{~mm})\end{array}$ & 0.4121 \\
\hline Internal partition/exterior wall & Concrete $(200 \mathrm{~mm})$ & 2.4823 \\
\hline \multirow[t]{2}{*}{ External/ceiling/floor } & $\begin{array}{l}\text { Concrete }(180 \mathrm{~mm})+\text { insulating material }(20 \mathrm{~mm}) \\
+ \text { cultivated sandy soil }(40 \mathrm{~mm})+\text { polystyrene }(40 \mathrm{~mm})\end{array}$ & 0.9565 \\
\hline & $\begin{array}{l}\text { Double glazing: clear float }(6 \mathrm{~mm})+\text { cavity }(12 \mathrm{~mm})+\text { clear } \\
\text { float }(6 \mathrm{~mm})\end{array}$ & 2.7387 \\
\hline External glazing & $\begin{array}{c}\text { Glass data: conductivity }(1.06 \mathrm{~W} / \mathrm{mK}) \text {, transmittance }(0.78) \text {, } \\
\text { outside reflectance }(0.07) \text {, outside reflectance }(0.07), \\
\text { refractive index }(1.526)\end{array}$ & \\
\hline Roof & Plaster $95 \mathrm{~mm}+$ concrete $200 \mathrm{~mm}$ & 1.1400 \\
\hline
\end{tabular}

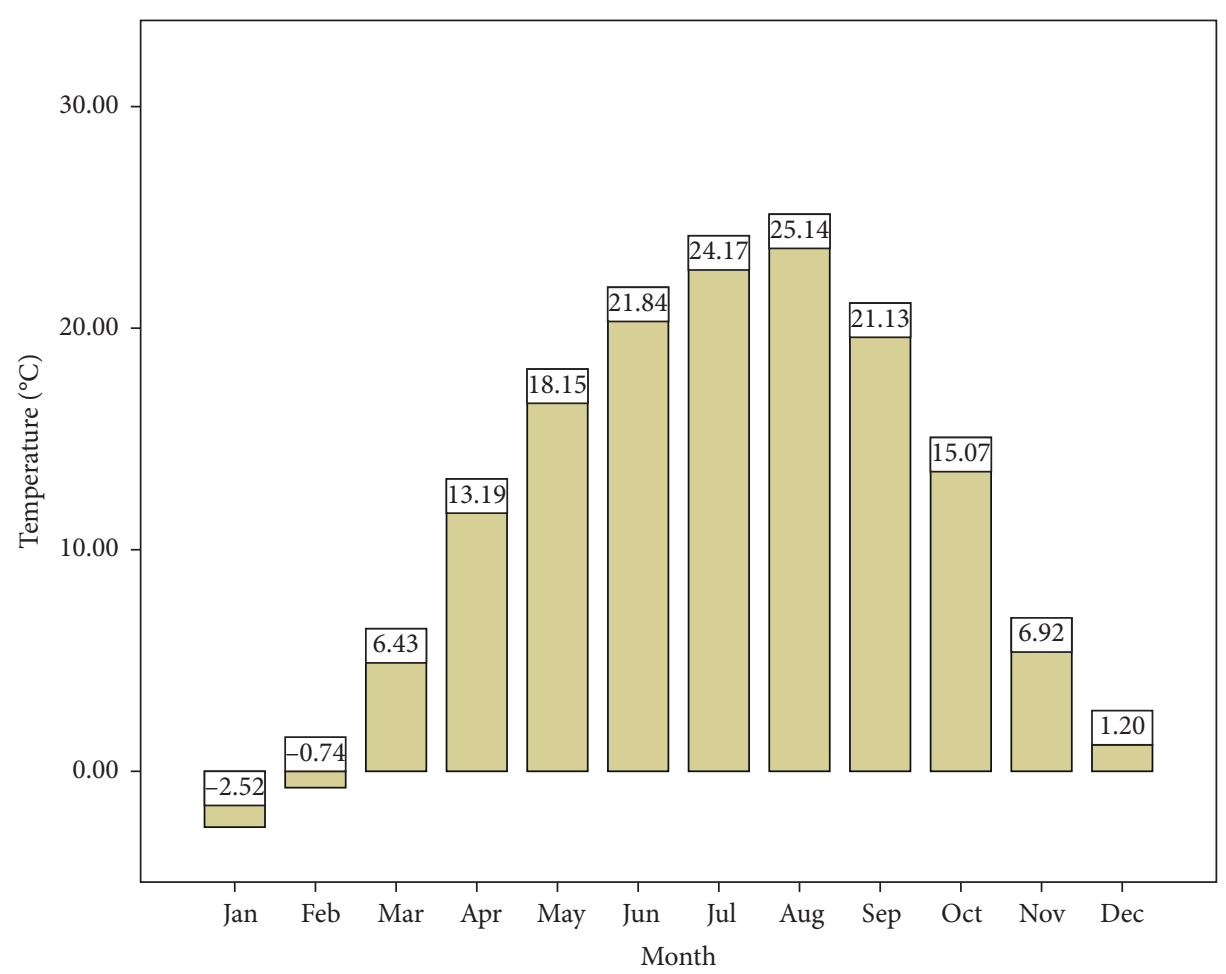

Figure 7: Monthly mean temperature during 30 years (1981 2010).

altitude. As such, solar radiation is usually highest during the summer period. However, solar radiation is shown to be the highest in April because the solar radiation from June to August is reduced owing to the concentration of precipitation (Figure 9).

Figure 10 shows the monthly solar radiation for Seoul with the highest direct solar radiation at $205 \mathrm{~W} / \mathrm{m}^{2}$ in April and the smallest at approximately $70 \mathrm{~W} / \mathrm{m}^{2}$ in January.

Overall, direct solar radiation tended to increase as the amount of global solar radiation rose. There was a slight discrepancy in rankings between July, August, and September.

4.2. HeatingLoad. The discrepancy between the heating load and the cooling load was about 8 times more than that experienced in Korean weather. The heating load was calculated from September to March, and its peak load was found to be in January. The results also indicated large differences in the heating load between months due to the concentration of seasonal loads. The highest value of the heating load was 0 for $x$ with no non-air-conditioned space. When the value of $x$ was increased however, the heating load linearly reduced as shown by the function in Figure 11.

In this paper, heating and cooling loads are expressed in $\mathrm{kW} / \mathrm{m}^{2}$. The trend showed by the graph lines in Figure 11 depicts typical linear equations. However, the values of two $y$-intercepts were not matched according to the width/depth ratios. The two calculated slopes of the equations being negative means that $x$ is inversely proportional to the heating load. In addition, the slopes for the absolute values were 2.4344 and 3.1813 for the $1: 1$ of width/depth ratio and $4: 1$ of width/depth ratio, respectively. Consequently, the sensitivity of $4: 1$ of width/depth ratio was higher than that of $1: 1$ of width/depth ratio by about 1.3 times. 


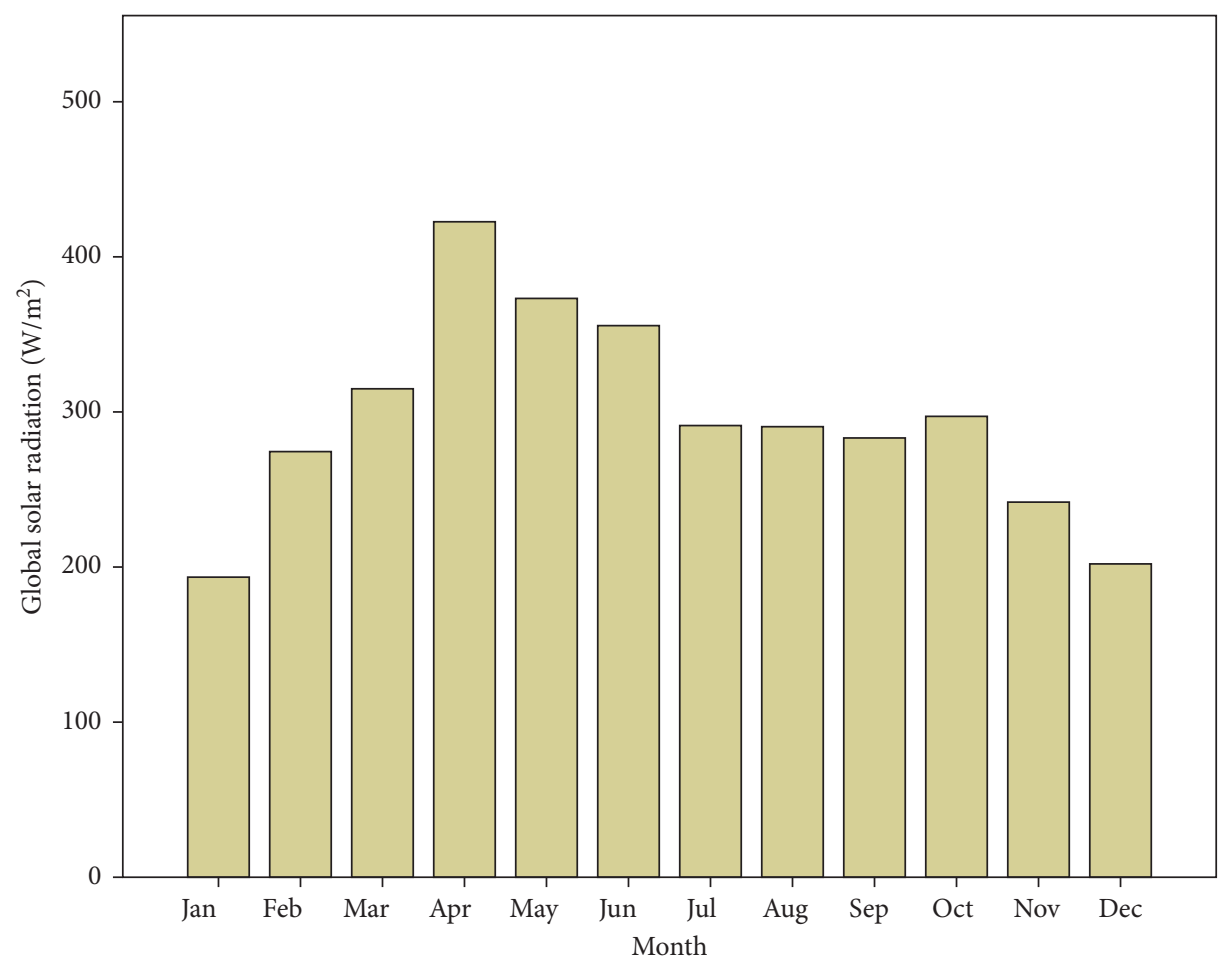

FIGURE 8: Monthly global solar radiation during 30 years (1981 2010).

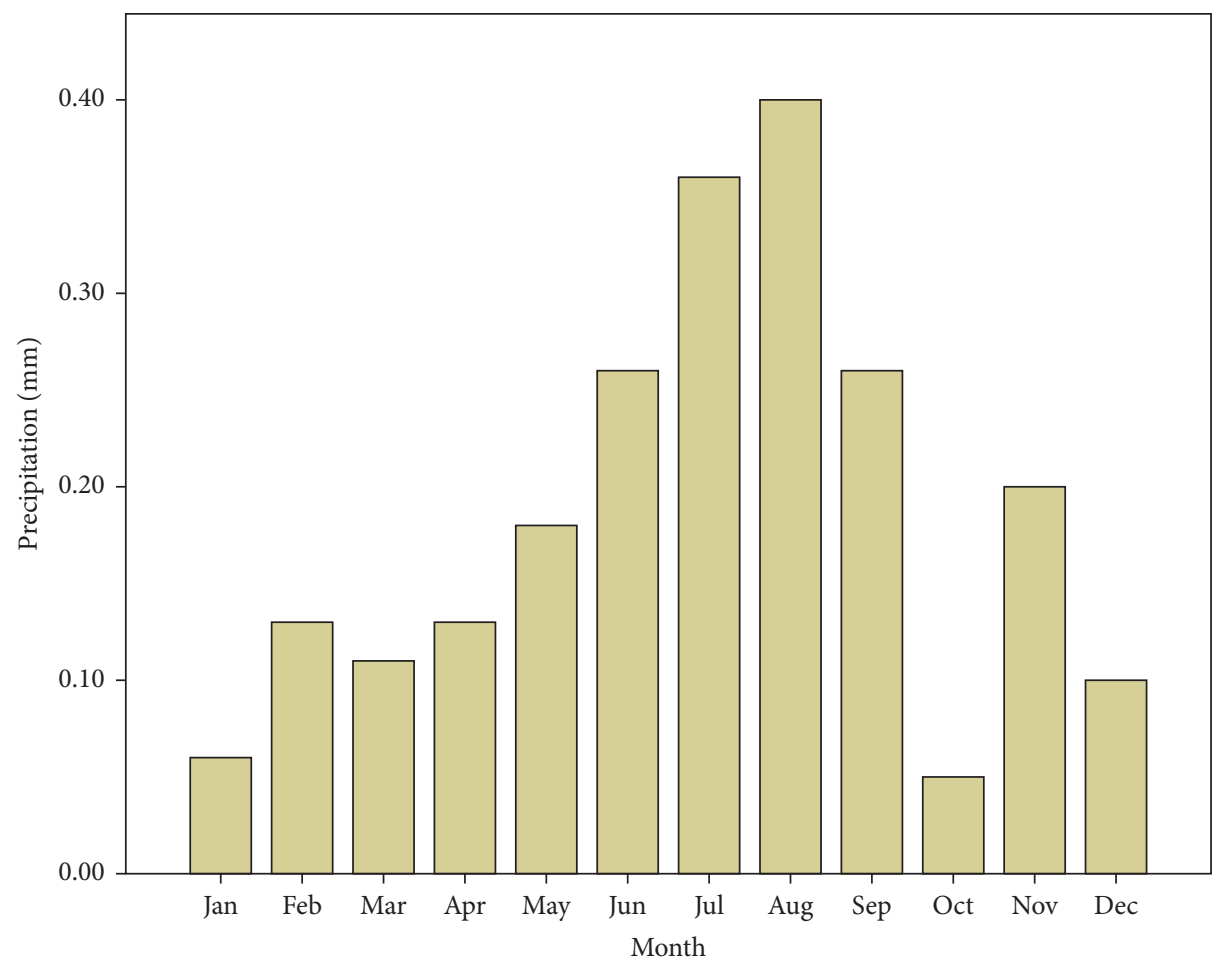

FIGURE 9: Monthly precipitation water during 30 years (1981 2010).

Regardless of width/depth ratio, two trend lines are converged when the $x$ value was constantly increased. For the case of the $x$ value being 90 , the discrepancy showed by the lines was found to be about $1 \mathrm{~kW} / \mathrm{m}^{2}$. In aggregate, the value of $4: 1$ of width/depth ratio was higher than that of $4: 1$ of width/depth ratio in terms of heating load. Although direct sunlight has an effect on heating load, the building facades facing north are relatively larger. This means that the role played by the building orientation outweighs that played by solar radiation. 


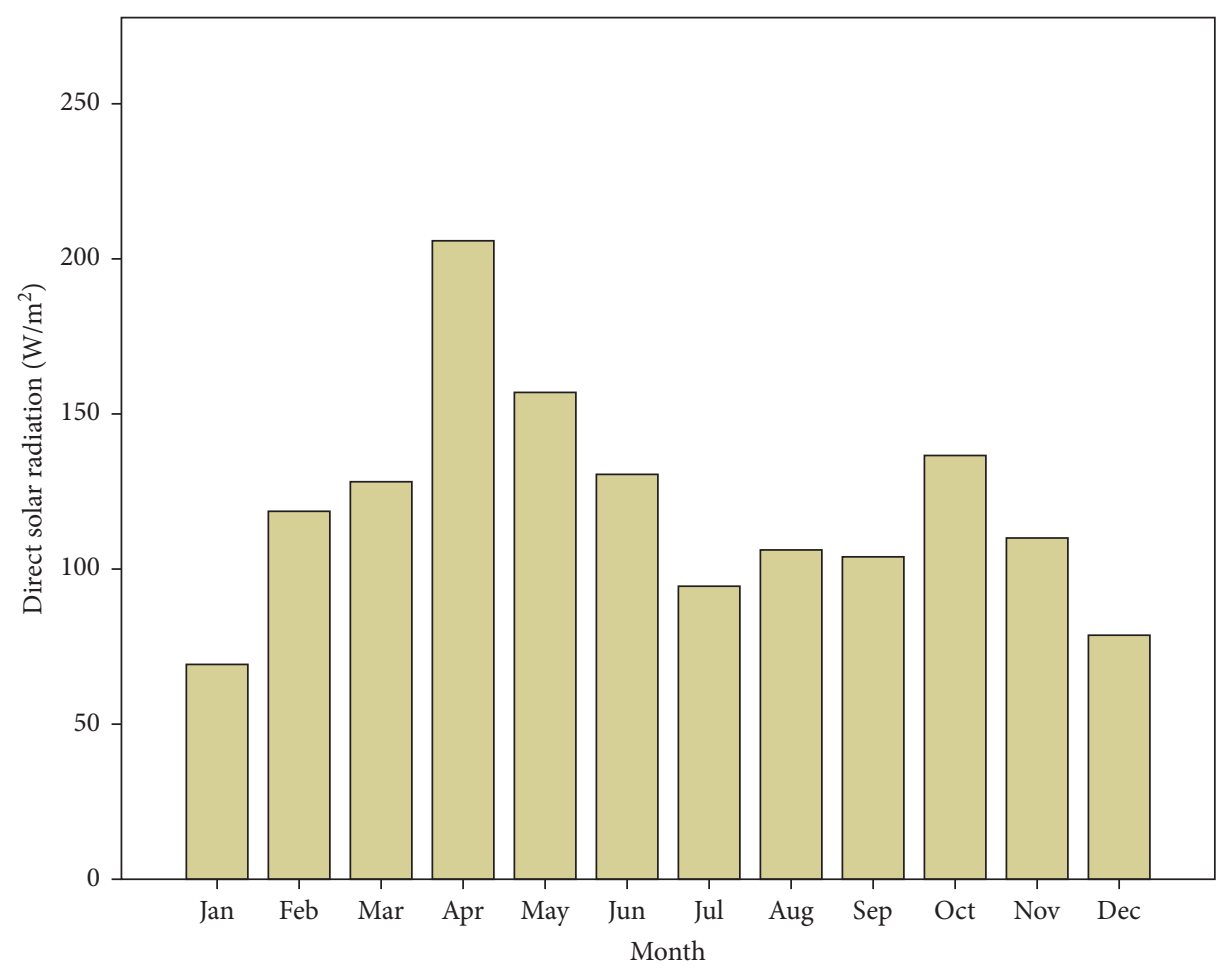

Figure 10: Monthly direct solar radiation during 30 years (1981 2010).

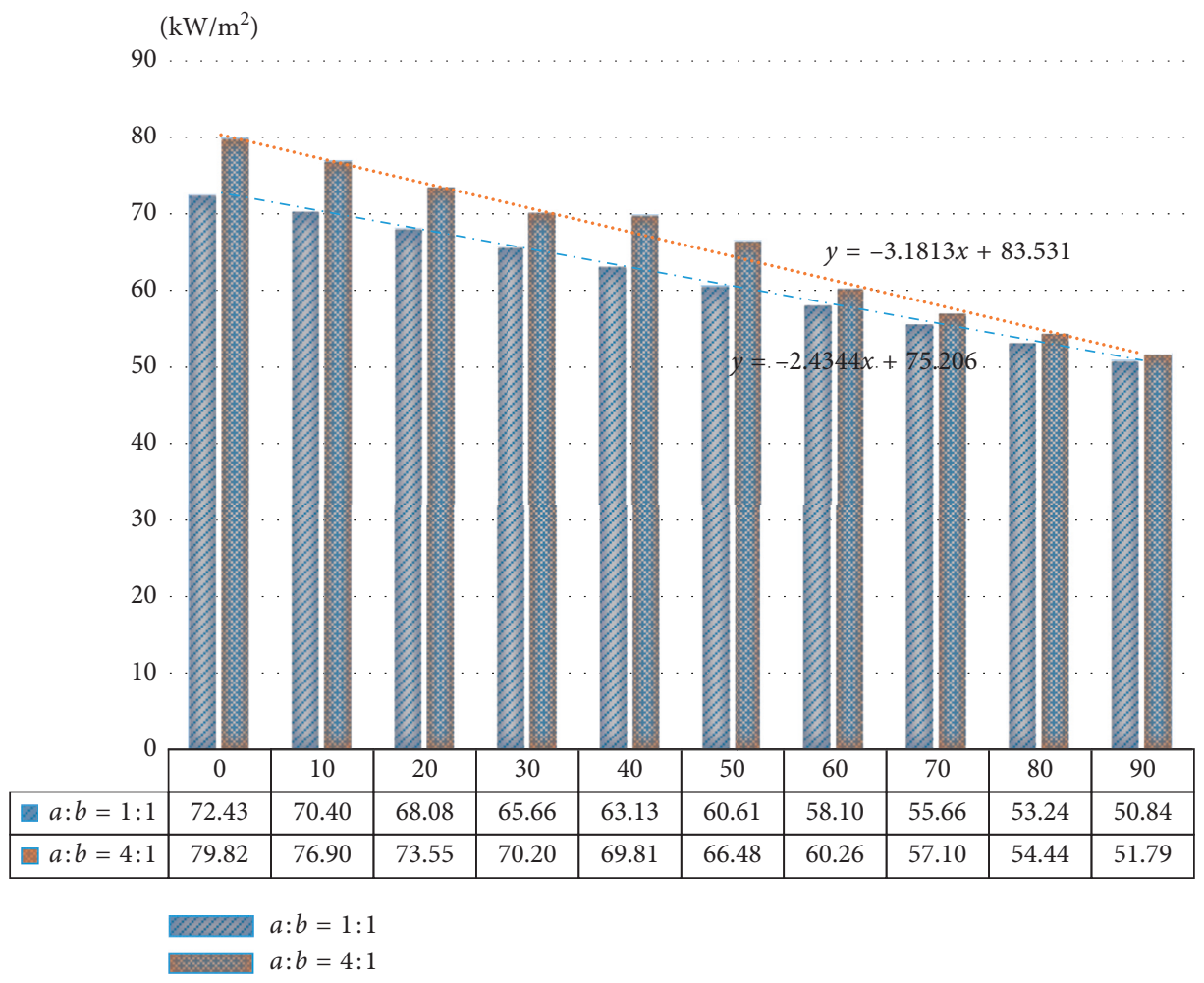

Figure 11: Heating load related to the $x$ value.

4.3. Cooling Load. Figure 12 shows the variation of the cooling load according to the $x$ value. Generally, the cooling load was affected by direct sunlight and natural ventilation performance, which largely depends on the opening ratio of windows. However, in this research, the variables were created by the arrangement of exposed envelopes between 


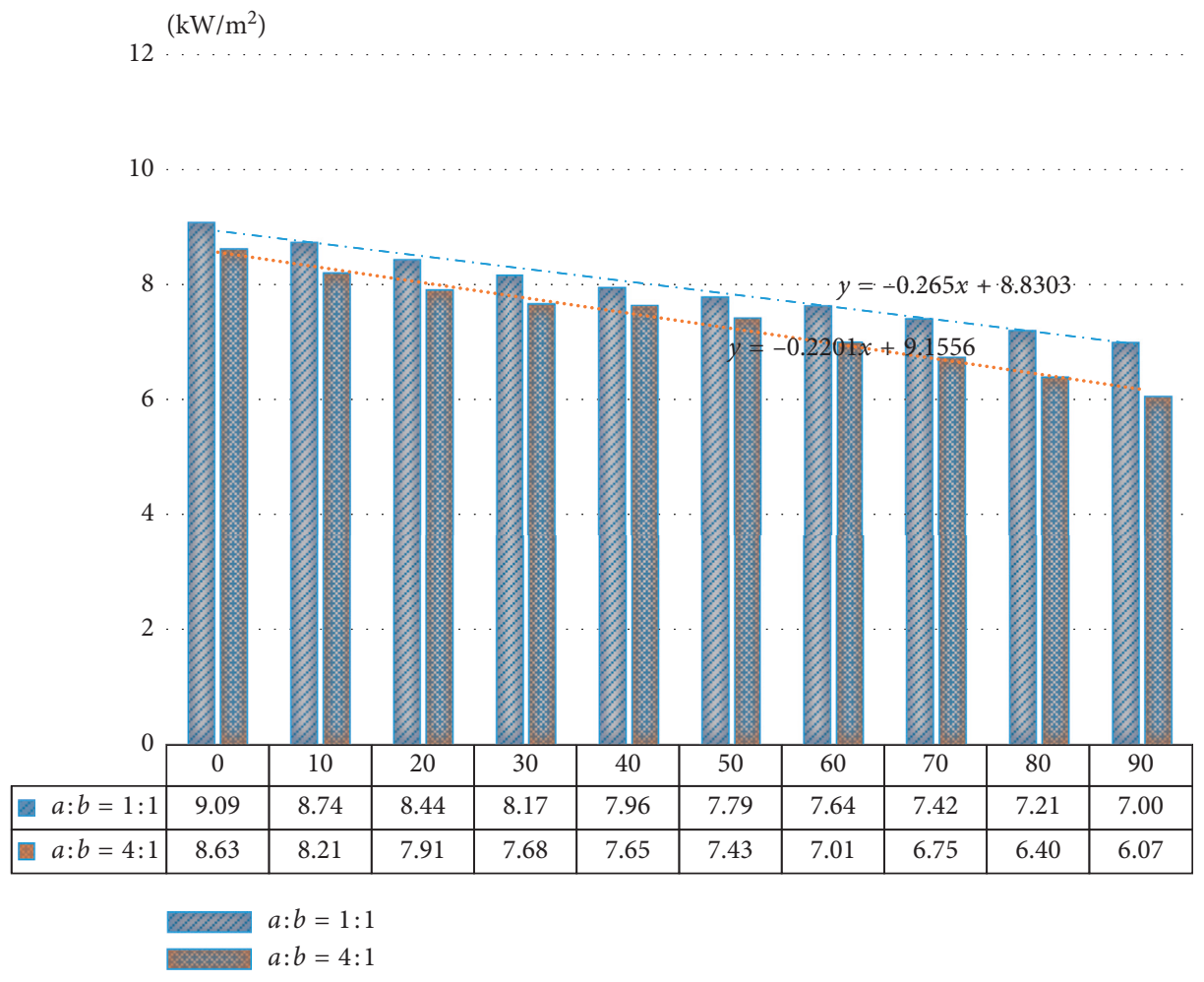

FIgURE 12: Cooling load related to the $x$ value.

the air-conditioned space and non-air-conditioned space. The shape adopted by Figure 8 is similar to the graph of the heating load. The trend line is denoted by the linear function showing that both the $x$ value and the load increased regularly independent of the width/depth ratio.

For the slope following the width/depth ratio, $1: 1$ of width/depth ratio was 0.2201 and $4: 1$ of width/depth ratio was 0.265 . Conclusively, energy loads depended much on width/depth ratio. The gaps of the two trend lines were changed if the $x$ value increased. In the heating load, the gap was reduced. On the other hand, the cooling load of the gap increased. In addition, the cooling load of $4: 1$ of width/depth ratio was lower than that of $1: 1$ of width/depth ratio whereas the heating load showed a counter trend. Table 2 shows the predictive results of heating and cooling load as the $x$ value is varied.

The impact of increasing the ratio $a: b$ shows the same tendency for both cooling load and heating load. Firstly, as the ratio $a: b$ increases, the gradient coefficient of each equation decreases. This means that the relationship between the ratio $a: b$ and sensitivity of heating and cooling load is inversely proportional. Secondly, the gradient coefficient of heating load is more than 10 times in same condition of the ratio $a: b$ according to the $x$ value.

\section{Conclusion}

This paper studied the effect of the size of non-airconditioned areas surrounding air-conditioned spaces on building energy consumption. Simulation analysis techniques were used to establish specific target spaces and to
TABle 2: Predictive results of heating and cooling load according to variations in $x$ value.

\begin{tabular}{llc}
\hline Variables & Building load & Predictive equation \\
\hline$a: b=1: 1$ & Cooling load & $y=-0.265 x+8.8303$ \\
& Heating load & $y=-3.1813 x+83.531$ \\
$a: b=4: 1$ & Cooling load & $y=-0.2201 x+9.1556$ \\
& Heating load & $y=-2.4344 x+75.206$ \\
\hline
\end{tabular}

produce and compare cooling load and heating load. The simulation software IES_VE was used for the simulations. The weather data of Seoul in South Korea collected by the Korea Meteorological Administration were used for energy performance evaluation. The results show the overall importance of factors such as temperature, global solar radiation, direct solar radiation, and precipitation on building energy consumption. Additionally, the results show that heating needs are approximately 8 times higher than cooling needs in Korean residential buildings. We also found that the gradient coefficient of the developed model generally reduced for both cooling and heating loads as the widthto-depth ratio increased (i.e., from $a: b=1: 1$ to i.e., $a: b=4: 1)$. Furthermore, the cooling load tended to be higher in spaces with the same width-to-depth ratio than in spaces where the width-to-depth ratio was $4: 1$. For heating load however, the reverse was observed.

The usage of conventional energy sources in buildings for the purposes of heating has become of serious concern. This is particularly due to the costs associated with these conventional energy sources as well as their effect on the environment [17]. As such, modern buildings should be able 
to minimize the usage of these energy sources. One way to achieve such a goal would be through the control of the interior surrounding conditions of the building relative to the external environmental conditions. Furthermore, it has been illustrated by and through the results obtained by the current study that to provide comfortable indoor conditions for building occupants, building parameters such as building façade orientation, building shape, and insulation should be given proper concern by building designers.

\section{Conflicts of Interest}

The authors declare that they have no conflicts of interest.

\section{References}

[1] G. Kim and J. T. Kim, "Healthy-daylighting design for the living environment in apartments in Korea," Building and Environment, vol. 45, no. 2, pp. 287-294, 2010.

[2] F. Goia, "Search for the optimal window-to-wall ratio in office buildings in different European climates and the implications on total energy saving potential," Solar Energy, vol. 132, pp. 467-492, 2016.

[3] H. Menkhoff, A. Blum, M. Trykowski, and W. Aapke, Energetisches Batten. Energiewirtschaftliche Aspekte zur Planung und Gestaltung von Wohngebauden, 04.086/1983, Schriftenreihe Bau-und Wohnforschung des Bundesministers fur Raumordnung, Bauwesen und Stadtebau, Bonn, Germany, 1983.

[4] K. Petzold, "Zeim einfluss von Form und Grösse der Gebäude auf den heizenergiebedarf," Luft-und Kältetechnik, vol. 19, no. 3, pp. 130-135, 1983.

[5] A. AlAnzi, D. Seo, and M. Krarti, "Impact of building shape on thermal performance of office buildings in Kuwait," Energy Conversion and Management, vol. 50, no. 3, pp. 822-828, 2009.

[6] W. Pessenlehner and A. Mahdavi, "Building morphology, transparence, and energy performance," in Proceedings of the Eighth International IBSPA Conference, Eindhoven, Netherlands, August 2003.

[7] P. Depecker, C. Menezo, J. Virgone, and S. Lepers, "Design of buildings shape and energetic consumption," Building and Environmslbent, vol. 36, no. 5, pp. 627-635, 2001.

[8] B. Su, "Building passive design and housing energy efficiency," Architectural Science Review, vol. 51, no. 3, pp. 277-286, 2008.

[9] C. S. Ling, M. H. Ahmad, and D. R. Ossen, "The effect of geometric shape and building orientation on minimising solar insolation on high-rise buildings in hot humid climate," Journal of Construction in Developing Countries, vol. 12, no. 1, pp. 27-38, 2007.

[10] I. G. Capeluto, "Energy performance of the self-shading building envelope," Energy and Buildings, vol. 35, no. 3, pp. 327-336, 2003.

[11] C. Ratti, D. Raydan, and K. Steemers, "Building form and environmental performance: archetypes, analysis and an arid climate," Energy and Buildings, vol. 35, no. 1, pp. 49-59, 2003.

[12] K. H. Lee, Construction Environmental Plan, Moon Woon Dang Inc., Seoul, South Korea, 3rd edition, 2007.

[13] M. Gough and C. Rees, Tests performed on ApacheSim in accordance with ANSI/ASHRAE Standard 140-2001, Illuminating Engineering Society of North America, Glasgow, Scotland, 2004.

[14] G. Kim, L. Schaefer, and J. T. Kim, "Development of a doubleskin facade for sustainable renovation of old residential buildings," Indoor and Built Environment, vol. 22, no. 1, pp. 180-190, 2012.

[15] E. Gratia and A. De Herde, "Design of low energy office buildings," Energy and Buildings, vol. 35, no. 5, pp. 473-491, 2003.

[16] R. Geiger, "Klassifikation der Klimate nach W. Köppen," in Landolt-Börnstein-Zahlenwerte und Funktionen aus Physik, Chemie, Astronomie, Geophysik und Technik, alte Serie, pp. 603-607, Springer, Berlin, Germany, 1954.

[17] U. T. Aksoy and M. Inalli, "Impacts of some building passive design parameters on heating demand for a cold region," Building and Environment, vol. 41, no. 12, pp. 1742-1754, 2006. 


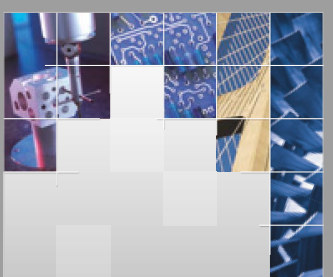

\section{Enfincering}
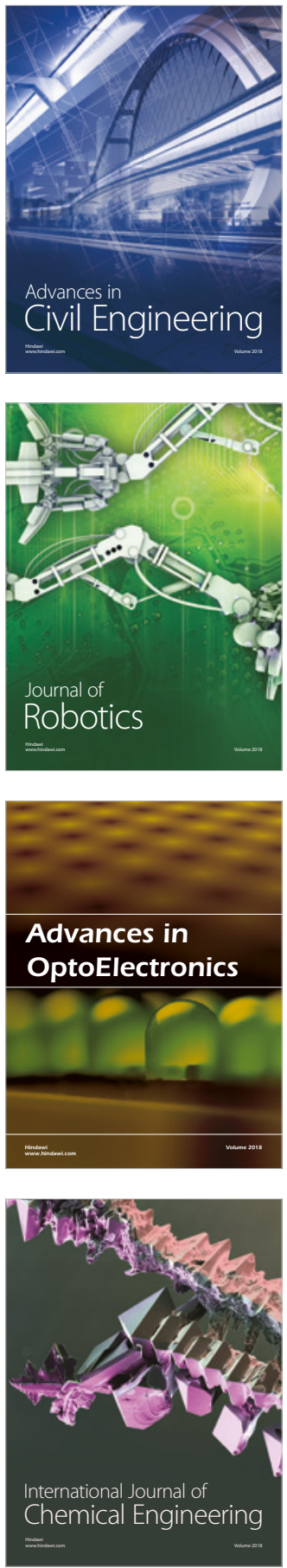

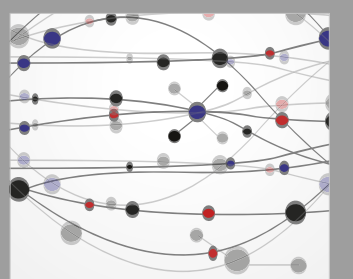

\section{Rotating \\ Machinery}

The Scientific World Journal

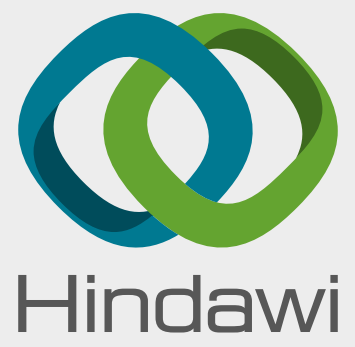

Submit your manuscripts at

www.hindawi.com
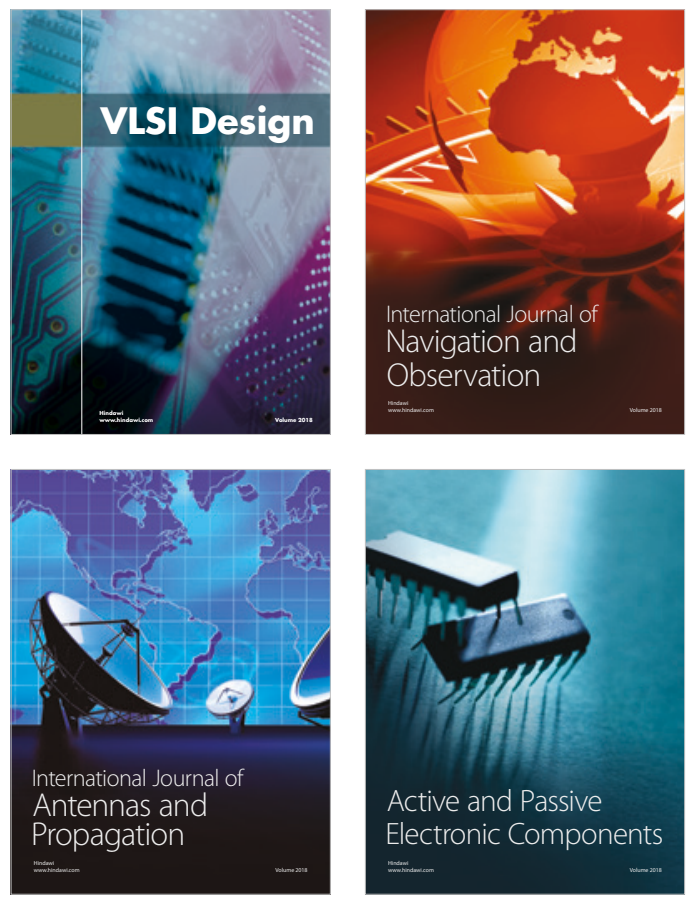
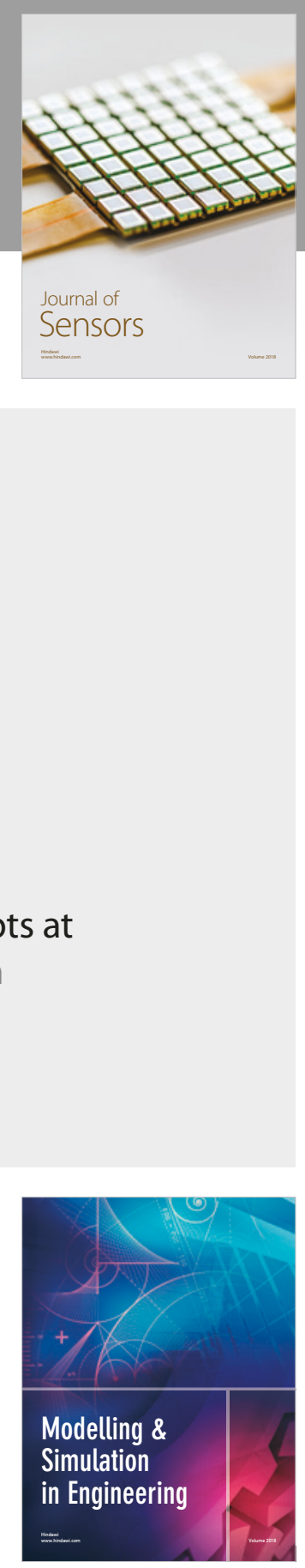

\section{Advances \\ Multimedia}
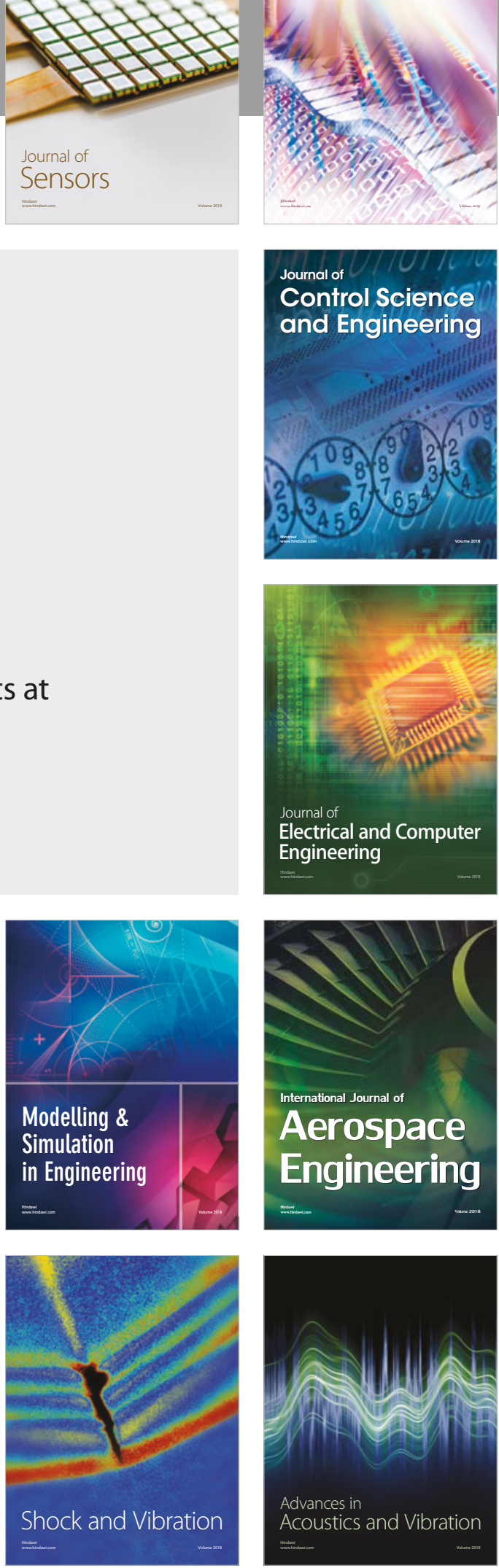